\title{
Archaeolinguistics As A Way To Overcome The Impasse In Comparative Linguistics
}

\author{
Wolodymyr H. Kozyrski ${ }^{1,}{ }^{*}$, Alexander V. Malovichko ${ }^{2}$ \\ ${ }^{1}$ The International Physical Encyclopedia Bureau, Mathematical Modeling Laboratory \\ at The Bogolubov Institute for Theoretical Physics, Kiev, Ukraine \\ ${ }^{2}$ Physics Laboratory, The Lyceum at The National Technical University "KPI", Kiev, Ukraine \\ kozyrski@ukr.net
}

\begin{abstract}
The paper exposes some essential points of our one and a half decade research results within new approach to study prehistoric stages of human language development mainly in times of ergaster-erectus domination and reflects our reaction to the protracted conceptual crisis in the comparative linguistics. As a result of fundamentally incorrectly stated goals, most of the researchers artificially limited themselves both by the defined scope of the problems to solve and by the methods used. Becoming tightly tied knot of up to now unsolved intrinsic contradictions, today comparative linguistics needs radical change. We have developed a synthetic approach that has proved its effectiveness. Our model is well aligned with prehistoric data of auxiliary historical disciplines and even IBM Genographic project. The results offer further opportunities for interesting studies.
\end{abstract}

Indexing terms/Keywords : Archaeolinguistics, Comparativistics, Ergaster-Erectus, Language Families, Vocabulary Enrichment

Subject Classification : Comparative Linguistics

Language : English

Date of Submission : 2017-12-23

Date of Acceptance : 2018-01-06

Date of Publication : 2018-02-28

ISSN : 2348-3024

Volume : 09 Issue : 01

Journal : Journal Of Advances In Linguistics

Publisher : CIRWORLD

Website : https://cirworld.com

This work is licensed under a Creative Commons Attribution 4.0 International License. 


\section{INTRODUCTION}

Exclusively complicated and probably completely inexplicable phenomenon, human language origin still excites thought and imagination of today researchers. May be, one cannot recover the first conscious use of human language from existing rich scientific information in various disciplines from comparative linguistics to the latest achievements in paleoarchaeology and paleogenetics.

Nevertheless, our mind can penetrate rather deeply into the past epochs, not only historical, but also prehistoric ones (in the conventional sense of the lack of written evidence). And the best guide to the prehistoric stages of humanity is its ancient and ever young creature, a living organism, continually accompanying it,namely, the human language.

We have over fifteen years experience in rather successful attempts of such synthetic penetrating into the prehistory of ethnic groups and their languages. The books $[1,2]$ contain some fragments of these studies. The papers $[3,4]$ show awareness of more recent information and the corresponding new considerations.

Despite the relatively young age of linguistics as the human language science (slightly more than two centuries), it has significant and undeniable success. It is enough to mention the names of Wilhelm von Humboldt, Alfredo Trombetti, Holger Pedersen, Vladislav Illich-Svitych, Joseph Greenberg, Sergei Starostin as the authors of outstanding scientific works in linguistics.

Over two-century comparative studies draw upon a simple and clear idea of common origin of the human race and language, inherent to it. On the one hand, such a comparative historical linguistic activity despite the triviality and even tautology has as quite reasonable academic ground the need to understand why languages and language families can look very similar.

However, the true information strength of linguistic knowledge as sources to clarify and build consistent picture of human culture prehistory is properly invaluable so far. Obviously, it is much wider and even immense problem within comparative studies themselves. However, experience of human searching thought development shows that the most interesting and important scientific achievements get lucky at the crossroads of scientific fields and disciplines, ie, synthetic science is much more productive than highly specialized speculations.

We think the comparative studies of basic vocabulary and vocabulary of the first prehistoric cultural layers with attached information from the auxiliary historical disciplines as archeology, paleontology and paleogenetics do set up those foundations of prehistoric human culture, from which better understanding of the cultural development of the human race on this planet will grow. Probably because natural imperfection of artifacts' and events' age determining one hardly be lucky to build full temporal sequence of absolute dates for cultural development of humanity. However, it is quite real to get a sequencing for appearance and spread of some prehistoric cultural achievements from some ethnic groups to other ones, basing on lexical material of language families with the addition of the above mentioned facts from auxiliary historical disciplines.

Our experience [1-4] confirms this statement and can serve as a ground for a new paradigm of modern comparative studies, significantly expanding the range of investigated problems and transferring the main research front from an abstract academic imaginary plane of the so-called protoforms' reconstructions that, according to the comparativists themselves can not be older than 1016 thousand years to the study of quite real specific prehistoric processes involving human communities well-known to paleoarchaelogists.

It's no secret that the correct problem formulation is most of its solution. Therefore, a new paradigm of modern comparative studies must protect its effective progress in acquiring new knowledge about the prehistory of human culture.

The paradox of the existing state of affairs in the linguistics is the fact that its real cognitive opportunities very often met (in fact, also still) fierce resistance by officious mafiosi, whether in the Paris 
Linguistic Society time, 1866 ban to deal with the origin of language, or later "scientific schools", definitely measuring the research value by its relevance to their own understandings.

The harm of such activities for free and fair development of scientific knowledge needs no explanation. However, despite a widespread assertion that history does not teach anyone anything, one must take the lessons from the historical facts being often rather enlightening.

\section{SOME CHECK-POINTS OF COMPARATIVE LINGUISTICS}

The above-mentioned example of unscientific rough diktat in 1866 is characteristic one in methodological sense. This forcing of free scientific thought was contagious and imitative for many later "near"scientific corporations such as "Indo-Germanists" and others like them. It closed for many years the way to free studying the world's languages and the relationship between them.

American linguist Merritt Ruhlen reflected this episode in 1991 in the Soviet journal "Linguistics' Problems" [5]. This prohibition shows that the "pillars" of the Paris Linguistic Society did not realize what they are doing with. Is it possible to prohibit the science? And another question: Is it a science that one can prohibit. It is the 1-st missed opportunity.

There was a possibility when linguistics should completely lose all its perspectives. Fortunately, some researchers have disobeyed the ban and linguistics developed further.

Poor linguists' knowledge both in the languages they study and in the use of some mathematical techniques caused the second braking force, namely, absolute misunderstanding of two closely related principal issues: the time of the human origin and the time of language occurrence. It is the 2 -nd missed opportunity of linguistics.

This is about the approvals of modern "leading" linguists that the humanity has age about 20-30, maybe, 40 thousand years, and according to the exponential law of lexical changes in any language modern languages can not contain any word elder than 10-16 thousand years.

Comments to this vicious allegations go beyond the subject of this article. We note only that today paleoarchaeology estimates the humanity age as elder than 2 million years. A factor multiplying time in the noted exponent is "sucked", to put it mildly, out of nowhere.

Serious-minded Indo-Germanic studies gave a number of fundamental results, including its own change into Indo-European studies, whose progressivism clouded many minds for a long time, especially linguists' ones. The twentieth century was the century of Indo-European studies as linguists mainly have engaged exclusively in Indo-European languages.

It is just unclear why the huge army of Indo-Europeists can not show even now when and where Indo-European languages might first appear. One can found a number of hypotheses on the IndoEuropeans' and their languages' homeland in SA Burlak and SA Starostin [6]. It is 3-rd missed opportunity of linguistics.

We tolerate a situation that different species of hominids lived closely in Africa and had various languages, which gradually disappeared, except one, that lived to the present day. Obviously, the languages at that stage of development were primitive. There one can not do without the conditions we defined earlier (see, e.g., [7]). The main condition for the language development is from simple to complex. The systematic disregard of this law is the 4-th major missed opportunity of linguistics.

It is important also to understand why Starostin differentiated two approaches to the study of the language history. In his interview called "Two approaches to study the history of language" ("Knowledge itself is power". - M., 2003, № 8) [8] (in Russian), Starostin opposes glottogonic approach to the comparative one identifying last with the reconstruction method.

Characterizing Greenberg's technique [9] based on the so-called method of mass comparison, Starostin notes: "In our opinion, this is such a heuristic definition by an eye"[8] (emphasis added - 
Auth.). If he had read the entire book of Greenberg, probably he would have refused this sentence. It is the 5-th missed opportunity of linguistics.

Add that in our opinion, there is no reason for the two approaches, but only one, based on a real Homo ergaster-erectus vocabulary, lived to our time. This vocabulary, which early erectus have used, eventually turned into Niger-Congo spoken language. Speakers of these languages have survived to our time, including the American Indian language speakers (Amerind).

After a 2003 interview, SA Starostin and SA Burlak have written a new book about Indo-European languages, almost completely ignoring the languages of Africa [6]. In this book, they gave only two or three pages to African languages and other languages.

If we rely on their uncritical perception of the glotto-chronological formula by Swadesh, comparative studies as such on the scale of more than 10,000 years waste their meaning. However, apart from loud dead-end statements, the authors stress that the language history (of course, all languages) has twenty or thirty thousand-year limit.

Nevertheless, there is a belief that at the beginning a single language was in the world. Alfredo Trombetti proclaimed this hypothesis explicitly [10].

Previous citations concern only Indo-European languages. And when we have to investigate not only the Indo-European languages? In this case, it is necessary, perhaps, to offer some ways out of the situation.

Barulin wrote about this stalemate quite frankly [11]. He admitted that "... we have three logical possibilities: language arose before the Cro-Magnon, the language emerged simultaneously with the Cro-Magnon, and the language appeareded later than the Cro-Magnon. There are many supporters of the first hypothesis among biologists, anthropologists, linguists, and philosophers. Although, I must say that the arguments in favor of a solution still lack a scientific foundation. "

And further: "From the passages mentioned, the authors of linguistic papers come from the view that language was born before the Cro-Magnons, or about the time of their development as a species. No serious argument."

Thus, today, after two centuries of self-motivated research, Indo-Europeists have no any perspective. It is 6-th missed opportunity of linguistics.

To exit from this difficulty, it would worthy to offer some new idea that allows you to discover significant new prospects. Rely upon old ideas means to lose time in vain. Here we present one such productive idea.

Studying the lexical materials to compare the propinquity of different languages, we were quite surprised that Bengtson and Ruhlen did not notice the fact completely changing the idea of the languages' and their speakers' history [12]. Even Greenberg himself did not analyze his own work in this respect [9].

What is it? The first chapter of the book "The Languages of Africa" by Joseph Greenberg examines African language macrofamily Niger-Congo [9]. However, the author did not pay attention to the universal principle of development prevailing in reality reflected in any study, namely, from simple to complex.

It is clear that the words of the two sounds are simple, and the words of the three (or more) sounds (or letters) are complex ones. Apparently, the words spoken by Niger-Congo macrofamily are simple. Niger-Congo languages' lexicon has words consisting only of two sounds. Here we give a few words, their form, and meaning: 1) water (from the Looma language) zi, zie, zia; 2) Eye ne, ni, nia; 3) cut te, de, ta; 4) know ma, (mania); 5) the child ba, be, bi; 6) talk ti, te, ta; 7) stone ta, tal, tale; 8) fire RT, woti, moto; 9) large da, dada, didi; 10) missed kam, kab, kap; 11) fall ti, te, to; 12) fish kal; and others. 
A small number of words cited here shows their naturalness. On the contrary, it is clear that a large number of primary words, i.e., words with which any language begin, is unnatural. Can we say that such a small amount of the first words of any language is natural? Absolutely, because in this way, according to our opinion, a universal principle of developing something new performed. Moreover, not only quantitatively but also qualitatively.

Thus, we have identified vocabulary, which had never been isolated and not used. It is, therefore, in general, remained unknown. To detect and show it, we have succeeded thanks to the outstanding work of Joseph Greenberg.

In addition, let specially emphasize that in the preceding discussion we are talking about the basic vocabulary as such without specifying its grammatical forms. This means that primary language vocabulary was completely same, even though it belongs to any language.

Unfortunately, all the linguists have completely ignored this phenomenon, including the author, Joseph Greenberg. It is the 7-th and perhaps most important missed opportunity of linguistics.

We should pay attention to the fundamental work of Bengtson and Ruhlen "Global Etymologies" [12]. The paper has a lot of interesting ideas. However, these ideas somehow did not advance linguistics forward.

What do we mean? Further linguistics promotion is impossible without the results obtained within other historical disciplines. Therefore, we rely on a number of publicly available facts obtained by paleoarheologists, paleogeneticists, and, naturally, by historical linguists.

As for the problem of the first human language appearance, according to our opinion, the "primary" language could occur only where the first man himself appeared. That human is now called Homo ergaster-erectus.

We know that species Homo ergaster-erectus appeared in the Equatorial Eastern Africa in the Great Rift Valley about 2-2.5 million year ago and immediately began to "travel". First, over Africa, and then he went outside of his native continent. Thus the very early hominids found himself in the southern part of Eurasia. South Caucasus was among them. See the results of archaeological excavations in South Georgia in the village of Dmanisi $[13,14]$. Numerous paleoarheologists believe that this is the first migration wave of early Homo erectus outside Africa.

A second migration wave occurred in about a million years after the first one from the lands where people speaking Chadian and Cushitic languages live up to our time. In our classification, as in the IllichSvitych book, this phylum has the name Nostratic macrofamily. Greenberg held almost the same view [9]. So, A. P. Derevyanko wrote [15] that about 450 - 350 thousand year B.C. the second migration flow began to move to Eurasia. At many new areas of human populations, this flow met groups of the first migration wave, and there is a mixture of two industries, namely, pebble and late Acheul.

Linguists consider such a transition model as satisfactory one. The model we proposed significantly alters these perceptions. Our model states: Homo erectus appeared in the Great Rift Valley about $2-2.5$ mln years ago. These early Homo erectus groups (not tribes) settled across Africa. They preferred especially Central and West Africa. As for the Homo erectus language, mentioned groups, probably much later have already spoken various languages. The first language of Homo erectus, as we mentioned above, was the language, which became the basis of Niger-Congo superfamily languages.

The route out of Africa, as the Genographic Project of IBM map shows [16], laid to the northeast of the human homeland. That is, these people crossed the Bab-el-Mandeb and settled on the southern coast of the Arabian Peninsula. But first, as IBM Genographic Project Figure shows, starting at 2 million years ago, Homo ergaster-erectus divided itself into two streams: Homo ergaster and Homo erectus [17]. Paranthropus had ceased to exist with the beginning of the second million year ago without the "offspring". As the diagram shows, a Homo ergaster graph starts after dividing of the previous flow into two streams. It happened about 1.8 million years ago. 
Current papers on the issue do not mention lands held by Homo erectus in that time. No one ever spoke of its fate. We do not know and have never the ability to get on to the last stage of the life of this species - Homo erectus. Of course, this fact plays a big role in our construction indicating a very late "disappearance" of Homo erectus as human species. According to our opinion, this human has not disappeared anywhere. Most likely, it really lived up to our days.

How far to the east this human populated South Asia and how long it took him to this promotion, is quite difficult to say. It settled Pakistan, India, southern China. According to archaeologists, human has occupied the vast territory no later than one mln years ago. A.P. Derevyanko wrote: "North migration wave of ancient human populations across the Middle East penetrated into Iranian territory and then to the Caucasus and possibly Asia Minor. Convincing evidence of this settlement is one of the outstanding in Eurasia location of Dmanisi (East Georgia) $[13,14] . "$ And further: "There is one thing of no doubt: the man took a million years to gradually populate the vast lands from Africa to the Pacific and Indian Ocean. However, the history and development of human culture happened in one species environment of Homo erectus [15]."

Based on these quotes, we can say that one of the major mistakes of archaeologists and linguists is that they consider the first person to appear in the Middle East. It is 8th missed opportunity of linguistics.

\section{OUR MODEL AND HOW IT WORKS}

Therefore, the archaeologists would have to explain the relation between the first and second migration flows. As to the arguments of linguists, it is necessary to remember (as we have already said) that Nostratic languages include Cushitic and Chadian languages. These were the first Nostratic languages, i.e., the earliest ones, whose homeland was very far from the Middle East, almost in the center of Africa. Based on these data, we propose a model of these languages' origin. In our model, the earliest macrofamily on the African continent was the Niger-Congo language phylum. The IBM Corporation Genographic Project www.nationalgenografic.com [16] map confirms the model. Genographic Project was published in 2011.

On the map [16], one can see two sources of human appearance: after the hominid Homo ergastererectus appeared on the territory of Equatorial East Africa, it for nearly a million years (maybe more) spread over the Africa, including the west lands of the continent and, of course, beyond. We do not think that erectuses could enter the territory of the Congo Basin virgin forests. Rather, they preferred to live in savannah. So they mostly settled lands of the East African Rift Valley, where came to the sea and crossed the Strait of Bab el Mandeb. Then and later, they likely occupied the territory of Central and West Africa. This route is shown on the map [16].

We have not yet discussed the forms of "primary" language found by Joseph Greenberg. In the book "Languages of Africa" [9], he proposed a hypothesis that in Africa carriers of 6 language macrofamilies lived (and live up to our time), of which only one macrofamily could be the most ancient, if, of course, one shares the Trombetti opinion that first the world had unique language.

The sense of the hypothesis, saying simply, is that the first words were invented, so to speak, by the "first couple" and their successors continued the race, before they reach our age. We think the "first couple" could really exist. Otherwise, you'll have to come up with some other pattern of occurrence and distribution of human over Earth.

From the beginning of his scientific career, Joseph Greenberg decided that this language could be one of the Afro-Asiatic ones in Nostratic phylum. For J. Greenberg, it was the main argument. Later, the language began to spread, first over Africa, and later over the globe. 
However, in this case we meet another problem, to which Greenberg could not cope. The question is, where there was a specific homeland of Afro-Asiatic languages. Of course, the answer could be twofold. First, in Africa. Second, in the Middle East.

We are, of course, happy with the first option, because for the second case, the beginning of all people would has be not Africa, but the Middle East, which contradicts to established facts.

Today, the spread of ancient humans routes already known. On the Map cited, we see the two routes, the beginning of which were, first, within Equatorial East Africa (or more precisely, in the Great Rift Valley). The second route begins with migration in Central and West Africa. The difference between the two routes that first appeared "immediately" after the hominid species Homo ergaster-erectus emerged, that is, two million years ago. And the second was formed only after 1.5 million years after the first. We repeat: the end of the two routes is the end of the African part of the path these people crossed the Strait of Bab el Mandeb.

As we mentioned above, this map shows two sources of this hominid genes appearance. One source is an area marked on the map by Luhya (Webuye, Kenya) and Maasai (Loitokitok, Kenya). The second source was in the lands of West African language speakers Yoruba (Ibadan, Nigeria) and the Chadian (N'Djamena, Chad).

Analyzing the Map, one would think that the two sources occurred at the same time and moved towards the Strait of Bab el Mandeb. And another mistake: the descendants of Homo erectus likely have different vocabularies. In fact, we think the source of languages are as follows: the language, appeared in West Africa, continued "primary" Niger-Congo lexicon. The Table 1 ensures this.

For almost one and a half million years, as we have said above, Homo erectus spread to the west. During this time his vocabulary absorbed new words (in addition to the original ones). In Table 1, we can see an example of language spoken in West Africa as a supplement to the "primary" Niger-Congo language vocabulary. The same thing happened with the Nostratic languages vocabulary accompanied by Chadian and Cushitic vocabulary. The main difference between the flows of migrants is that the first stream started 2 million years ago, and the second one only $450-350$ thousand years ago. That is, the second thread has appeared in one and a half million years after the first.

Naturally, one can assume that the vocabulary of the streams was different. But it turned out that the vocabulary of the carriers of the second stream extended the vocabulary of the first one. This phenomenon we show in Table 1. It is our main conclusion.

The same we prove, considering Hominid evolutionary tree (Smithsonian Institution) [17]. About 2 million years ago, there was a kind of hominids, namely Homo ergaster-erectus, continuing the previous two species, Homo rudolfensis and Homo habilis. Later Homo ergaster-erectus divided itself into two branches, one of which, Homo erectus, became independent and has survived to the present day. Second, Homo heidelbergensis, has evolved over time to species Homo neanderthalensis and Homo sapiens, the latter of which became dominant in the world.

Thus we explain the evolution from the vocabulary of Niger-Congo languages to Nostratic languages' vocabulary, including Cushitic and Chadian as a part of the Afro-Asiatic languages, by the fact that they arose after Homo erectus appeared, whose language, according to our assumptions, was the language of the African Niger-Congo phylum.

Now we have more recent information confirming the foregoing considerations. Take a look at Table 1, containing the primary Niger-Congo vocabulary and Afro-Asiatic one of Nostratic phylum (Illich-Svitych Dictionary [18]). We think the Table 1 provides some first dictionary words with common roots.

Symbols in Table 1: Languages NC - Niger-Congo, Nostr. - Nostratic, including Alt. - Altaic languages, S.-H. - Afro-Asiatic, Kart. - Kartvelian languages. Alt. languages include Turk. - Turkic, TM Tungus, Mong. - Mongolian, Kor. - Korean language, Jap. - Japanese. St. - Altai vocabulary from 
Starostin book [19]. We use various languages of Africa and Eurasia. Amerind - vocabulary of Americas languages [20]. SSO is "the Kartvelian vocabulary" by Sulkhan-Saba Orbeliani, published in the Georgian language in the eighteenth century. [21]

TABLE 1

\begin{tabular}{|c|c|c|c|c|}
\hline \multirow{2}{*}{$\mathbf{N}$} & \multirow{2}{*}{ Word } & \multicolumn{3}{|c|}{ Phylum } \\
\hline & & Niger-Congo & Nostratic & Amerind \\
\hline 1 & water & Looma zi, zie, zia & $\begin{array}{l}\text { Alt.St*suwV(Tat.stw) Kart.sweli, } \\
\text { sueli - 'wet' }\end{array}$ & 856 *si, $863 c^{\prime} i$ \\
\hline 2 & fire & Swahili moto, ot, woti & $\begin{array}{l}\text { Il-Sv343 *qot'i'burn','fire' S.-H. } \\
\text { ht'/ht' 'ignite','catch } \\
\text { fire'West.Cush.*Ht Wolamo ètt; } \\
\text { Gimirra ot -'cook,','bake'; Kaffa } \\
\text { att(i) 'set afire'; Mocha 'àt't'a - } \\
\text { 'catch fire' Alt. St. } 81 \text { *ot'V: Turk. } \\
\text { *ōt, anc. Turk *ōt }\end{array}$ & $272 *(?)$ oti \\
\hline 3 & eye & $\begin{array}{l}\text { Susala ni,Mossi ni(fu) Susu } \\
\text { nia,Dan nya,Nafana nie(ne) }\end{array}$ & Alt. St. 21*ńiā: TM ńiā-sa & $\begin{array}{c}251 \text { *nak } \\
\text { Nivkh: niakh }\end{array}$ \\
\hline 4 & cut & $\begin{array}{l}\text { Bwamu ta, Kpelle,Nyang- } \\
\text { bo, Bassa, Guand, Mbuam } \\
\text { te,Zande de Niger Saharan } \\
\text { Dinka, Nandi tem }\end{array}$ & & 168 *t'an, $170{ }^{*} \mathrm{t}^{\prime} \mathrm{ek}^{\prime}$ \\
\hline 5 & know & $\begin{array}{l}\text { ProtoBantumanya-know' } \\
\text { Ibo, Mbum ma - 'think', } \\
\text { 'mind', 'understand' }\end{array}$ & $\begin{array}{l}\text { Il-Sv } 281 \text { *manu - 'think' S.-H. mn } \\
\text { 'think','understand','want' } \\
\text { EastCush. Somali mān-'mind' } \\
\text { West. Chad 'know', 'understand' } \\
\text { Bolewa mon,Angas,Ankwe, Mon - } \\
\text { tol, Sura man,Masa min-'want' }\end{array}$ & $423{ }^{*} \mathrm{ma}(\mathrm{k}) \sim \mathrm{ma}(\mathrm{n})$ \\
\hline 6 & child & $\begin{array}{l}\text { Hoke ba,ProtoBantu biad, } \\
\text { Gbaya be, Mossi bi, Bariba } \\
\text { bii }\end{array}$ & $\begin{array}{l}\text { II-Sv } 32 \text { *b/r^S S.-H.bir;Cush Sakho } \\
\text { bār'a, bāl'ā, Afar- bāl'ā - 'child', } \\
\text { Darasa belti 'son',belto } \\
\text { 'daughter';St314*bāldV Turk. bälä, } \\
\text { TM*baldi -'born'Kart.bere }\end{array}$ & 128 *pan, 131 *pam \\
\hline 7 & fish & Looma (arch.) - kala & $\begin{array}{l}\text { Il-Sv } 155 \text { *kal^: S.-H.EastCush. } \\
\text { *klm; Somali kállūn, kellūn.Chad } \\
\text { *klph -'fish'; WestChad. Hausa kifi, } \\
\text { Bura kölfa Alt.St362 *k'olV: TM } \\
{ }^{*} \text { xol-sa -'fish'Kart. kalmaxi - trout }\end{array}$ & $289 *^{*} \mathrm{k}^{\prime} \mathrm{al} \sim \mathrm{kal}$ \\
\hline 8 & many & Looma moin, moin & $\begin{array}{l}\text { St. Alt.45*mānV:Kor.*mān(h) Jap. } \\
{ }^{\star} \text { mania }\end{array}$ & 475 *moni \\
\hline 9 & tell & $\begin{array}{l}\text { Proto Bantu ti, Awuna, } \\
\text { Adele, Ewa te - 'tell', Bini, } \\
\text { Efik te, Bini ta }\end{array}$ & $\begin{array}{l}\text { Alt.St202*tē- 'tell', Turk. }{ }^{\star} \text { dē } \\
\text { anc.Turk., Chuvash. te; Kart. titini - } \\
\text { (SSO - 'chatter') }\end{array}$ & $618 * \mathrm{ti}$ \\
\hline 10 & two & $\begin{array}{l}\text { Messo bala, Nalu bele, } \\
\text { Nimbari bola }\end{array}$ & & 821 *(ne)pale \\
\hline
\end{tabular}




\begin{tabular}{|c|c|c|c|c|}
\hline 11 & stone & $\begin{array}{l}\text { Kasele, Adele (de)ta, Bua, } \\
\text { Gbaia ta, Kam tal, Kamuku } \\
\text { tale }\end{array}$ & $\begin{array}{l}\text { Alt. St68 *tiola (Turk. }{ }^{*} \text { dal) Kart. t'ali } \\
\text {-'flint' }\end{array}$ & 721 *tak \\
\hline 12 & catch & Swahili kamata & $\begin{array}{l}\text { Il-Sv190*k'aba/kap'a S-H qb-take } \\
\text { catch, bite, Cush. *qb: Sakho kab- } \\
\text { take, catch, Somali qab -take, } \\
\text { keep, have, Galla qab - catch, } \\
\text { keep, Chad Bolewa n-gab-u - I'm } \\
\text { fishing Alt.St318*k'ap'V -catch, } \\
\text { keep, Turk.*kap TM *xap-ki, Kart. } \\
\text { k'b -'bite' SSO xapangi - trap' }\end{array}$ & $\begin{array}{l}\text { 137*q'ap(a) - сжать, } \\
\text { закрыть }\end{array}$ \\
\hline 13 & big & Looma bala, bolo & $\begin{array}{l}\text { II-Sv350*wol(a) S-HCushBedja } \\
\text { w:u/i/ē:n; Somali wejn; Chad Angas } \\
\text { warn, Sura wúrán, Bura walaka, } \\
\text { Margi ’wál, Musgu wēl; old } \\
\text { Slav.Velımy - very }\end{array}$ & 62 *pala \\
\hline 14 & $\begin{array}{l}\text { big } \\
\text { tall }\end{array}$ & $\begin{array}{l}\text { Warwar Mambila da - be } \\
\text { long, ProtoBantu *dai, } \\
\text { Niang dada 'be long,high', } \\
\text { Mbum, Banda di, Ewe didi }\end{array}$ & $\begin{array}{l}\text { I-S66*did } \wedge \text { - big S-H d(j)d 'big', } \\
\text { 'fat'; Chad. Gider dide - 'big'; Kart. } \\
\text { did - 'big' }\end{array}$ & $\begin{array}{l}427{ }^{*} \operatorname{ta}(\mathrm{k})-\mathrm{b}^{\mathrm{big}} \text { ', } \\
\text { 'large' }\end{array}$ \\
\hline 15 & belly & $\begin{array}{l}\text { Kissi puli, Mossi pu(ga) } \\
\text { Dagomba puri, } \\
\text { ProtoBantu*pu, Barambo } \\
\text { bulu, Mumuye buru }\end{array}$ & $\begin{array}{l}\text { St.3 *päjlV-'belly' Turk. bēl. Mong. } \\
\text { feligen, Kor. păi, Jap. pàrá }\end{array}$ & 57 *pal(i) \\
\hline 16 & fall & $\begin{array}{l}\text { Nzakara, Zande, Gbanziri } \\
\text { ti, Bwaka, Mba, Banda te }\end{array}$ & & $255 *$ tik \\
\hline 17 & tortoise & $\begin{array}{l}\text { ProtoBantu*kudu, Susu } \\
\text { kure, Bozo(Soninke) kun }\end{array}$ & Kart. ku & 820 *kuli (turtle) \\
\hline \multicolumn{5}{|c|}{ The next examples are not so evident. However, we included them into our TABLE } \\
\hline 18 & $\begin{array}{l}\text { Karp } \\
\text { (fish) }\end{array}$ & Swahili karapu Amhar. Karp & $\begin{array}{l}\text { Kart. k'orbu, Ital. carpa, Eng. carp } \\
\text { Ukr. karp, Chech. karp }\end{array}$ & $\begin{array}{l}\text { Tagal. karpa, Nivkh. } \\
\text { karp }\end{array}$ \\
\hline 19 & $\begin{array}{l}\text { goose }(2 \\
\text { nd stable } \\
\text { name is } \\
\text { Bati ) }\end{array}$ & $\begin{array}{l}\text { Swahili batabukuni - } \\
\text { goose, bati - duck }\end{array}$ & Kart. bati-goose & Miwok duck - watmal \\
\hline
\end{tabular}

\section{CONCLUSION}

If we had found a few more words in contemporary bilingual dictionaries of languages in Africa, you could get a complete table of the primary language. However, up to now most of Earth's languages has no such dictionaries. Therefore, in our table, we have gaps filled with individual dictionaries and books. For some words, we were forced to use random sources.

Combining all these maps and tables, we get a universal table, which began in Africa and ended in America. Thus, we can to create a chain of words, starting from the oldest languages in Africa, that is, Niger-Congo phylum languages, through the Afro-Asiatic languages of Central Africa (mainly Cushitic and Chadian languages, Nostratic in origin), and through languages being today outside Africa (now we 
coped with Kartvelian and Altai languages' vocabularies only) to the Amerind languages. Homo erectus moved with its language over Eurasia to the East until occupied already all over America about 50 thousand years ago.

Our TABLE gives a solid foundation for the statement that Kartvelian languages' carriers very early settled South Caucasus. It referred to an ancient Dmanisi hominids [14]. These issues lie within the next stage of our research. In addition, we want to develop new promising idea as the Table we analyzed contained Altai vocabulary as a part of Nostratic one. We think, it is time to consider whether the Denisovan cave inhabitants spoke the Altai language. Moreover, they appeared not earlier (probably later) than 400 thousand years ago.

\section{REFERENCES}

1. Kozyrski, W.H., Malovichko, A.V. Language Prehistory. The Steel Publishing, Ltd. Kiev, 143p. (2012).

2. Kozyrski, W.H., Malovichko, A.V. Linguo-Ethnic Prehistory. The Steel Publishing, Ltd. Kiev, 144p. (2012). (In Ukrainian).

3. Kozyrski, W.H., Malovichko, A.V. To Human Language Origins. Journal of Language, Linguistics and Literature, 1, No 3, pp.86-93 (2015).

4. Kozyrski, W.H., Malovichko, A.V. Understanding Etruscan: A New Step. Journal of Language, Linguistics and Literature, 1, No. 4, pp. 137-144, (2015).

5. Ruhlen, M. Language Origin: Retrospective and perspective. Problems of Linguistics. № 1. 1991. Moscow

(in Russian).

6. Burlak, S.A., Starostin, S.A. Comparative Historical Linguistics. Moscow, 2005 (in Russian).

7. Kozyrski, W.H., Malovichko, A.V. Could prehistoric hunter language be retained?( Language nonogenesis III ). Origin of language and culture: ancient history of mankind, 1, № 4, 18-24, Kiev, 2007. (In Russian)

8. Starostin, S.A. Interview to Journal "Knowledge is Power Itself", № 8, 2003 (in Russian).

9. Greenberg, J. H. The Languages of Africa. Bloomington, Indiana. 1963.

10. Trombetti, Alfredo. L'unita d'origine del linguaggio. Bologna, 1905.

11. Barulin, A.N. Glottogonic theory and comparative historical linguistics. (in Russian).

21ru/Archive/2004/Barulin.htm.

www.dialog-

12. Bengtson, John D., Ruhlen, Merritt (1994), "Global Etymologies", in RUHLEN, Merritt, «On the Origin of Languages: Studies in Linguistic Taxonomy", Stanford: Stanford University Press, cc. 277-336

13. Dzaparidze V., Bosinski G., et al. Der altpaläolithische Fundplatz Dminisi in Georgian (Kavkasus) // Jahrbuch des Römisch-Germanischen-Zentralmuseums. - 1991. — Bd. 36. - S. 67 - 116.

14. Gabunia, L., Vukua, A., Lordkipanidze, D. New finds of fossil man bone remains in Dmanisi (Eastern Georgia) // Archaeology, Ethnology, and Anthropology of Eurasia - 2001. — № 2 (6). - 128 - 139. (in Russian).

15. Derevianko, A.P. The early human migrations in Eurasia and the problem of forming Upper Paleolithic. Archaeology, Ethnology, and Anthropology of Eurasia, 2(22), 22-36, 2005. (In Russian)

16. IBM Corporation Genographic Project: www.nationalgenografic.com .

17. Hominid evolutionary tree (Smithsonian Institution). 
18. Illich-Svitych, V.M. Experience of Nostratic Languages Comparison.V.1. Moscow, 1971; V.2. Moscow, 1976; V.3. Moscow, 1984. (In Russian)

19. Starostin, S.A. Altaic Problem and the Origin of the Japanese Language. Moscow, 1991. (In Russian)

20. Greenberg, J. H., Ruhlen, M. An Amerind Etymological Dictionary. - Stanford University Press. 2007.

21. Orbeliani, S.-S. Georgian Lexicon. Tbilisi, Georgia, 1928. (Russian translation from Georgian). 